\title{
안면마비 회복 예측에서 순목 반사의 역할
}

\author{
표소은, 박윤길, 박진영, 이주원
}

연세대학교 의과대학, 강남세브란스병원 재활의학과, 희귀난치성 신경근육병 재활연구소

\section{The Role of Blink Reflex in Predicting the Recovery of Facial Palsy}

\author{
Soeun Pyo, Yoon Ghil Park, Jinyoung Park, Joowon Lee \\ Department of Rehabilitation Medicine, Gangnam Severance Hospital, Rehabilitation Institute of \\ Neuromuscular Disease, Yonsei University College of Medicine, Seoul, Korea
}

\begin{abstract}
Objective: To determine whether blink reflex can be used as a prognosis test for Bell's palsy and whether it can complement the limitations of electroneurography (ENoG) as a prognostic test for Bell's palsy.

Method: This retrospective study included 99 patients diagnosed with Bell's palsy from August 2011 to January 2017. Findings of clinical examination of facial nerve function were recorded using the House-Brackmann scale at the initial visit and follow up examination was done at the second and third visit. Electrophysiological evaluations were performed using blink reflex and ENoG tests within one month of Bell's palsy onset. Clinical data were analyzed using Student's Tand Chi-square tests.

Results: Acceptable left side R1, R2 and abnormal right side R2 latencies or abnormal left side R1, R2 and acceptable right side R2 latencies of the blink reflex and poor clinical recovery measured by the House-Brackmann grade of patients with Bell's palsy showed a statistically significant correlation $(p=0.009)$. Likewise, in patients with an ENoG degeneration ratio less than 90\%, Acceptable left side R1, R2 and abnormal right side R2 latencies or abnormal left side R1, R2 and acceptable right side R2 latencies of the blink reflex and poor clinical recovery from Bell's palsy showed statistical significance $(p=0.015)$.

Conclusion: Blink reflex could be a prognostic factor for clinical recovery in patients with Bell's palsy. Furthermore, blink reflex could complement the limitations of ENoG as a prognostic test.
\end{abstract}

Key Words: facial palsy, blink reflex, prognosis

\section{Introduction}

Received September 29, 2017

Revised (1st) November 23, 2017, (2nd) December 30, 2017

Accepted January 19, 2018

Corresponding Author: Yoon Ghil Park

Department of Rehabilitation Medicine, Gangnam Severance Hospital, Yonsei University College of Medicine, 211 Eonjuro, Gangnam-gu, Seoul 06273, Korea

Tel: 82-2-2019-3490, Fax: 82-2-2019-7585, E-mail: DRTLC@yuhs.ac
Bell's palsy is a commonly observed cranial nerve VII dysfunction that can result in compromised facial appearance and function. It represents about 50\% to $60 \%$ of all etiologies of peripheral acute idiopathic facial paresis with a variable annual incidence in different regions ranging from 8 to 52.8 per 100,000
Copyright $\odot$ by Korean Association of EMG Electrodiagnostic Medicine
This is an Open Access article distributed under the terms of the Creative Commons Attribution Non-Commercial License (http://creativecommons.org/licenses/by-nc/4.0) which permits unrestricted non-commercial use, distribution, and reproduction in any medium, provided the original work is properly cited. 
persons. $^{1-3}$

Predicting the prognosis of this peripheral facial palsy is important for both clinical counseling and patient management. The natural course of Bell's palsy is encouraging, as total recovery is expected in 70 85\% of patients and a higher percentage of patients recover when oral corticosteroids are administered and early physical rehabilitation is performed for patients with severe paresis. ${ }^{4-6}$

Several electrophysiological tests have been used to determine facial palsy prognosis. Degeneration ratios by electroneurography (ENoG) and needle electromyography (EMG) are the most frequently studied tests. ${ }^{7-10}$ Some reports suggesting that a prolonged degree or absence of R1 and R2 by blink reflex can also be used to predict the prognosis. ${ }^{11-13}$ However, the value of these different electrophysiologic tests for outcome prediction in acute peripheral facial nerve palsy remains controversial.

In clinical settings, clinicians frequently explain the prognosis of facial palsy to patients based on the degeneration ratio by ENoG test, in which a ratio of less than $90 \%$ indicates a favorable prognosis in patients with Bell's palsy. But in reality, a considerable number of patients with degeneration ratios less than 90\% have unfavorable outcomes such as sustained facial paresis. It would be helpful to identify a complementary prognostic factor that can reinforce the degeneration ratio of the ENoG test.

The aims of this study were to determine whether the blink reflex can be used as a prognostic test for Bell's palsy and if the reflex can complement the limitations of ENoG as a prognostic factor for Bell's palsy. In contrast to previous studies that focused only on the efficiency of the ENoG test, this study evaluated the complementary prognostic value of blink reflex combined with the ENoG test.

\section{Materials and Methods}

\section{1) Subjects}

We retrospectively reviewed the clinical records of patients who underwent both blink reflex and ENoG studies in the electrodiagnosis laboratory of a tertiary metropolitan hospital between August 2011 and January 2017. A total of 215 patients were affected by pure unilateral Bell's palsy. Finally, 99 patients were enrolled; 116 patients were excluded because they were lost to House-Brackmann (H-B) scale follow-up or had a short follow-up duration (within two weeks).

\section{2) Clinical evaluation of facial nerve function}

Facial nerve function was recorded using the $\mathrm{H}-\mathrm{B}$ scale. The $\mathrm{H}-\mathrm{B}$ scale is based on a six-grade score, from normal to total paralysis that offers a gross evaluation of the facial motor function of the frontalis, orbicularis oculi, and orbicularis oris muscles. Findings of clinical examination of facial nerve function were recorded using the House-Brackmann scale at the initial visit and follow up examination was done at the second and third visit. The patients were categorized into recovered or non-recovered groups depending on their improvement as measured by the H-B scale.

\section{3) Electrophysiological evaluation}

Blink reflex and ENoG tests were performed using Synergy ${ }^{\circledR}$ (Oxford Medelec, Wiesbaden, Germany). Disposable adhesive surface electrodes were used with tests using Ambu ${ }^{\circledR}$ Neuroline 715 (Ambu, Baltorpbakken, Denmark). Electrophysiological evaluations were performed using blink reflex and ENoG tests within one month of Bell's palsy onset. The mean duration between the onset of disease and the day that blink reflex and ENoG tests were initially performed was $11.04 \pm 8.052$ days.

\section{(1) Electroneurography}

ENoG responses were measured on the affected and unaffected sides. The facial nerve was stimulated supramaximally at the stylomastoid foramen and the 
facial muscle compound action potential was recorded from the surface electrode placed at the nasolabial fold, beside the alar groove. The active electrode was positioned over the ipsilateral nasolabial fold and the reference electrode was placed laterally and contralaterally to the ala nasi. Amplitude was defined as maximum peak-to-peak trace displacement. Sweep speed was set to $5 \mathrm{~ms} / \mathrm{cm}$, sensitivity was $1000 \mathrm{uV} /$ division and frequency band was 10 10000 Hz. The degeneration ratio by ENoG was calculated as $100 \times$ (1 - [amplitude on the affected side/amplitude on the unaffected side]).

\section{(2) Blink reflex}

The blink reflex test was performed while the patient was lying supine in a relaxed state with the eyes either open or gently closed. Blink reflexes were obtained by applying electrical stimulation to the supraorbital nerve of one side. The surface recording electrodes were placed bilaterally over the inferior orbicularis oculi muscles. Two active recording electrodes were located bilaterally on the inferior orbicularis oculi muscles and reference electrodes were placed in the temporal region. The ground electrode was placed on the chin. Responses were defined as "acceptable", "prolonged" (ipsilateral R1 $\geq 13.1 \mathrm{~ms}$; ipsilateral R2 $\geq 41 \mathrm{~ms}$; contralateral R2 $\geq 44 \mathrm{~ms}$ ), or "no response"; the patients were divided into "no response or prolonged" and "acceptable" groups based on the ipsilateral R1, $\mathrm{R} 2$, and contralateral R2 latency responses.

\section{4) Statistical analysis}

The baseline characteristics of the participants were analyzed using Student's T-test. Chi-square tests were used to examine the correlation between patients' clinical recovery with ENoG tests and abnormal ipsilateral R1, R2, and contralateral R2 latency by blink reflex in Bell's palsy. Statistical analyses were performed using SAS ver. 9.2 for Windows (SAS Inc., Cary, NC, USA). The statistical significance level was set at a p-value of 0.05 .

\section{RESULTS}

\section{1) Patient characteristics}

The patients consisted of 50 male and 49 female patients with mean age of 47.3 years. Five patients had diabetes and 18 patients had hypertension. Among the 99 patients, the 56 who showed improvement in $\mathrm{H}-\mathrm{B}$ grade were classified as recovered, while the 43 patients who did not show $\mathrm{H}-\mathrm{B}$ grade improvement were classified as non-recovered. Age did not differ significantly between the two groups, with mean ages of 46.39 and 48.51 years in the recovered and nonrecovered groups, respectively $(p=0.49$ by chi-square test) (Table 1).

\section{2) Relationship between clinical recovery and neurophysiologic features}

Of the 56 patients in the recovered group, 30 patients (53.57\%) showed no response in the ipsilateral R1 or R2, 5 patients (8.93\%) showed prolonged R1 or R2 latencies and 21 patients (37.50\%) showed acceptable $\mathrm{R} 1$ and R2 latencies. In the non-recovered group, 35 patients $(81.40 \%)$ showed no response in the ipsilateral R1 or R2, 2 patients (4.65\%) showed prolonged R1 or R2 latencies and 6 patients (13.95\%) showed acceptable ipsilateral R1 and R2 latencies. The proportions of abnormal R1 or R2 latencies were $62.50 \%$ and $86.04 \%$ in

Table 1. Baseline Demographic and Clinical Characteristics of Patients Who Had Recovered and Not Recovered Patients from Bell's Palsy

\begin{tabular}{cccc}
\hline \hline Variable & $\begin{array}{c}\text { Recovered } \\
(\mathrm{N}=56)\end{array}$ & $\begin{array}{c}\text { Non-recovered } \\
(\mathrm{N}=43)\end{array}$ & $\mathrm{p}$-value \\
\hline Age & 46.39 & 48.51 & 0.49 \\
Sex & & $24(55.81)$ & 0.35 \\
$\quad$ Male & $26(46.42)$ & $10(44.18)$ & \\
Female & $30(53.57)$ & & 0.87 \\
DM & & $2(4.65)$ & \\
$(+)$ & $3(5.35)$ & $41(95.34)$ & \\
$(-)$ & $53(94.64)$ & & 0.92 \\
HTN & & $8(18.60)$ & \\
$(+)$ & $10(18.03)$ & $35(81.39)$ & \\
$(-)$ & $46(82.14)$ & &
\end{tabular}

Values are presented as number (\%) DM: diabetes mellitus, HTN: hypertension $*_{p}<0.05$ 
Table 2. Correlation between Blink Reflex and Clinical Improvement in All Included Subjects and in Those with Electroneurography Degeneration Ratio (DR) below $90 \%$

\begin{tabular}{|c|c|c|c|c|c|}
\hline Blink reflex & $\begin{array}{l}\text { Recovered } \\
(N=56)\end{array}$ & $\begin{array}{c}\text { Non-recovered } \\
(N=43)\end{array}$ & Sensitivity & $\begin{array}{l}\text { Negative predictive } \\
\text { value }\end{array}$ & p-value \\
\hline & & & $86.0 \%$ & $77.7 \%$ & $0.009 *$ \\
\hline Acceptable & $21(37.50)$ & $6(13.95)$ & & & \\
\hline Prolonged and no response & $35(62.50)$ & $37(86.05)$ & & & \\
\hline DR below $90 \%$ & $\begin{array}{l}\text { Recovered } \\
(\mathrm{N}=54)\end{array}$ & $\begin{array}{c}\text { Non-recovered } \\
\quad(N=36)\end{array}$ & Sensitivity & $\begin{array}{l}\text { Negative predictive } \\
\text { value }\end{array}$ & $p$-value \\
\hline & & & $83.3 \%$ & $78.5 \%$ & $0.015^{*}$ \\
\hline Acceptable & $22(40.74)$ & $6(16.67)$ & & & \\
\hline Prolonged and no response & $32(59.26)$ & $30(83.33)$ & & & \\
\hline
\end{tabular}

Values are presented as number (\%)

$* p<0.05$

the recovered and non-recovered groups, respectively, a statistically significant difference $(p=0.009)$ (Table 2).

The degeneration ratio was less than $90 \%$ in 90 patients, which implies a probable good prognosis according to previous studies. Among these patients, 54 patients had improved $\mathrm{H}-\mathrm{B}$ grade, while 36 patients did not. Among patients in the recovered group with a degeneration ratio less than 90\%, 32 patients (59.26\%) showed prolonged R1 or R2 latency or no response and 22 patients (40.74\%) showed acceptable R1 and R2 latency. Among patients in the non-recovered group with a degeneration ratio less than 90\%, 30 patients (83.33\%) showed prolonged R1 or R2 latency or no response and 6 patients (16.67\%) showed acceptable R1 and R2 latency. The proportions of abnormal R1 or R2 latencies were $59.25 \%$ and $83.33 \%$ in the recovered and non-recovered groups, respectively, a statistically significant difference $(\mathrm{p}=0.015)$ (Table 2$)$. The mean follow-up duration from disease onset was 52.48 days.

\section{DISCUSSION}

Bell's palsy is a peripheral type of facial nerve palsy; the most likely etiology is an idiopathic immune reaction after a viral infection. ${ }^{14-17}$ Although Bell's palsy causes paralysis of the facial musculature, it usually resolves in few weeks, leaving no trace of nerve damage. The reported rate of complete recovery from Bell's palsy ranges between $70 \%$ and $90 \% .{ }^{18}$ However, in some cases, the lesions do not completely recover. In these cases of incomplete recovery, the lesions may have resulted in axonal destruction with resultant Wallerian degeneration or temporary neural impulse blockade leading to residual paresis and abnormal branching of the regenerating axons. ${ }^{19,20}$ This can lead to clinically evident residual paresis. Therefore, early identification of patients with a poor prognosis is important if proper treatment, such as surgical management, can be undertaken prior to irreversible nerve damage. ${ }^{21-23}$

A number of methods are used to diagnose Bell's palsy and to determine its prognosis. Although it remains controversial which electrophysiologic test is ideal for the early determination of poor Bell's palsy prognosis, the degeneration ratio calculated from the ENoG is generally considered the best prognostic test. In addition, nerve excitability test, electromyogram (EMG), facial nerve latency test, and blink reflex are also known methods for evaluating the facial nerve. ${ }^{24,25}$ However, these additional tests have been shown to have limited prognostic value, ${ }^{24,26}$ with false-positive and falsenegative results.

On the other hand, some reports have shown that blink reflex is of great value in predicting the clinical outcomes of individuals with facial nerve palsy. ${ }^{11,27}$ In these reports, blink reflex was a useful prognostic indicator when conducted within the first 14 days after the onset; the persistence of or early return of an initially absent ipsilateral R1 component may suggest 
qualitatively satisfactory recovery of facial nerve function. In this study, the mean duration between the onset and the first study was 8.76 days, similar to previous studies. ${ }^{1,3}$

In addition, the lack of a response during the first two weeks after onset resulted in an unfavorable prognosis. In our study, blink reflex also showed significant prognostic correlation with improvement in $\mathrm{H}$-B grade $(p=0.009)$ (Table 2). This finding demonstrates that blink reflex could be a good prognostic test for clinical recovery from Bell's palsy.

A degeneration ratio less than $90 \%$ by ENoG testing indicates a favorable prognosis for patients with Bell's palsy. ${ }^{25}$ Therefore, surgeons tend to make decisions regarding surgical treatment in cases of Bell's palsy based on this degeneration ratio. ${ }^{28}$ However, in our study, among 90 patients predicted to have a good prognosis, with less than 90\% degeneration ratio by ENoG, 36 (40\%) actually had a poor prognosis. In these cases, if a clinician had explained that a patient with degeneration ratio less than $90 \%$ had a favorable prognosis after the ENoG study but the symptoms persisted, the doctor encounters an awkward situation and the patient becomes depressive and may blame the doctor. Therefore, our study demonstrated that blink reflex has additional prognostic value in these patients, as these results are significantly correlated with clinical recovery. In previous studies, the sensitivity of ENoG test in facial palsy patients was as low as 60\%. ${ }^{29}$ In this study, the sensitivity of blink reflex among patients with degeneration ratios less than $90 \%$ by ENoG was $83.3 \%$, which implies that the combination of the two studies can have better prognostic value (Table 2). Also in this study, the negative predictive value of blink reflex among patients with degeneration ratio less than $90 \%$ by ENoG was $78.5 \%$, which propose additional prognostic value predicting better prognosis in these patients. These results show that blink reflex is not only a good prognostic value by itself but is also a complementary test for ENoG, which is considered to be the best electrophysiological prognostic test.
Some studies reported age to be a prognostic factor for clinical recovery in Bell's palsy. ${ }^{30}$ One study showed that aging is a significant factor for final outcomes but not for the time to maximal recovery, suggesting that the course of recovery from facial palsy in elderly patients is similar that of younger patients. ${ }^{31}$ However, elderly patients do not recover the same degree of function as younger patients. In our study, there were no significant differences in age between the recovered and non-recovered groups, suggesting that age is not correlated with poor clinical outcomes ( $p=0.49$ ). Some studies investigated the role of diabetes mellitus on the clinical and electrophysiological parameters of peripheral facial palsy. ${ }^{32,33}$ In these studies, there were no significant differences between patients with and without diabetes mellitus, similar to the results of our study. However, with only five diabetic patients in our study, statistical analysis was impossible. Several studies suggested hypertension as a possible risk factor for peripheral facial palsy. ${ }^{34,35}$ In our study, 18 patients had hypertension; among them, 10 showed clinical recovery. Based on these results, hypertension does not have a significant prognostic correlation with improvement in $\mathrm{H}-\mathrm{B}$ grade ( $\mathrm{p}=0.92$ by chi-square test).

This study has several limitations. First, the number of patients was relatively small. Second, the mean duration between the onset of disease and the day that blink reflex and ENoG tests were initially performed was as short as $11.04 \pm 8.052$ days. Since ENoG tests reflect axonal degeneration of facial nerve, this short duration between the onset of disease and the day that ENoG tests initially performed can explain somewhat lower prognostic value compared to previous studies. Third, a common limitation of retrospective studies, the timing of the electrophysiological study and physical exam using the $\mathrm{H}-\mathrm{B}$ grade varied with diverse followup durations, as each patient had a different followup schedule depending on their symptom severity; patients with mild symptoms often did not visit the outpatient clinic on the scheduled date. Likewise, due to follow-up loss, the follow-up duration also varied 
with each patient and was often too short, about two weeks. And also, since there were only 11 patients who showed degeneration ratios greater than or equal to 90\%, selection bias may have affected the results.

Despite these limitations, this study has some strengths. A considerable proportion of patients with degeneration ratios below 90\% had unfavorable outcomes in this study and the combination of blink reflex and ENoG showed better prognostic value, offering more accurate and reliable estimates.

\section{Conclusion}

In conclusion, blink reflex is a valuable prognostic test in Bell's palsy patients. Furthermore, in patients with an ENoG degeneration ratio of less than 90\%, blink reflex can complement the limitations of the prognostic value of ENoG. Further study with a larger number of patients and controlled follow-up durations are needed.

\section{References}

1. Yanagihara N: Incidence of Bell's palsy. Ann Otol Rhinol Lryngol Suppl 1987: 137: 3-4

2. Hill MD, Midroni G, Goldstein WC, Deeks SL, Low DE, Morris AM: The spectrum of electrophysiological abnormalities in Bell's palsy. Can J Neurol Sci 2001: 28: 130-133

3. Peitersen E: Bell's palsy: the spontaneous course of 2,500 peripheral facial nerve palsies of different etiologies. Acta Otolaryngol 2002: 122: 4-30

4. Engström M, Berg T, Stjernquist-Desatnik A, Axelsson S, Pitkäranta A, Hultcrantz M, et al: Prednisolone and valaciclovir in Bell's palsy: a randomised, double-blind, placebocontrolled, multicentre trial. Lancet Neurol 2008: 7: 9931000

5. Nicastri M, Mancini P, De Seta D, Bertoli G, Prosperini L, Toni D, et al.: Efficacy of early physical therapy in severe Bell's palsy: a randomized controlled trial. Neurorehabil Neural Repair 2013: 1545968313481280

6. Sullivan FM, Swan IR, Donnan PT, Morrison JM, Smith BH, McKinstry B, et al.: Early treatment with prednisolone or acyclovir in Bell's palsy. N Engl J Med 2007: 357: 1598-1607

7. Gantz BJ, Rubinstein JT, Gidley P, Woodworth GG: Surgical management of Bell's palsy. Laryngoscope 1999: 109: 11771188

8. Sittel C, Stennert E: Prognostic value of electromyography in acute peripheral facial nerve palsy. Otol Neurotol 2001: 22: 100-104

9. Takemoto N, Horii A, Sakata Y, Inohara H: Prognostic factors of peripheral facial palsy: multivariate analysis followed by receiver operating characteristic and Kaplan-Meier analyses. Otol Neurotol 2011: 32: 1031-1036

10. Park JH, Kim KJ, Seok JI, Lee DK: Usefulness of Serial Eelctrophysiologic Tests for Estimating the Prognosis of Bell's Plasy. J Korean EMG Electrodiagn Med: 10: 107-112

11. Ghonim M, Gavilan C. Blink reflex: prognostic value in acute peripheral facial palsy. ORL J Otorhinolaryngol Relat Spec 1990: 52: 75-79

12. Mizukoshi K, Watanabe Y, Aso S, Asai M: Prognostic value of blink test in patients with facial paralysis. Acta Otolaryngol 1987: 104: 70-75

13. Kimura J, Giron LT, Young SM: Electrophysiological study of Bell palsy: electrically elicited blink reflex in assessment of prognosis. Arch Otolaryngol 1976: 102: 140-143

14. Bell C: On the nerves; giving an account of some experiments on their structure and functions, which lead to a new arrangement of the system. Philos Trans R Soc Lond B Biol Sci 1821: 111: 398-424

15. Adour KK, Bell DN, Hilsinger RL: Herpes simplex virus in idiopathic facial paralysis (Bell palsy). JAMA 1975: 233: 527530

16. Mulkens P, Bleeker J, Schroder F: Acute facial paralysis: a virological study. Clin Otolaryngol 1980: 5: 303-310

17. Murakami S, Mizobuchi M, Nakashiro Y, Doi T, Hato N, Yanagihara N: Bell palsy and herpes simplex virus: identification of viral DNA in endoneurial fluid and muscle. Ann Intern Med 1996: 124: 27-30

18. Sittel C, Sittel A, Guntinas-Lichius O, Eckel HE, Stennert E: Bell's palsy: a 10-year experience with antiphlogistic-rheologic infusion therapy. Otol Neurotol 2000: 21: 425-432

19. Holland NJ, Weiner GM: Recent developments in Bell's palsy. BMJ 2004: 329: 553-557

20. Grosheva M, Wittekindt C, Guntinas-Lichius O: Prognostic value of electroneurography and electromyography in facial palsy. Laryngoscope 2008: 118: 394-397

21. Weiju H: Surgical treatment of peripheral facial paralysis. J Otol 2012: 7: 78-81

22. Marais J, Murray J: Repair of the injured facial nerve. Clinical Otolaryngol 1995: 20: 387-389

23. Danner CJ. Facial nerve paralysis. Otolaryngol clin North Am 
2008: 41: 619-632

24. Dumitru D, Walsh NE, Porter LD: Electrophysiologic evaluation of the facial nerve in Bell's palsy: a review. Am J Phys Med Rehabil 1988: 67: 137-144

25. Fisch U: Prognostic value of electrical tests in acute facial paralysis. Otol Neurotol 1984: 5: 494-498

26. Esslen E: The acute facial palsies: investigations on the calization and pathogenesis of meato-labyrinthe facial palsies, Springer: 1977

27. Heath J, Cull R, Smith I, Murray J: The neurophysiological investigation of Bell's palsy and the predictive value of the blink reflex. Clinical Otolaryngol 1988: 13: 85-92

28. Fisch U: Surgery for Bell's palsy. Arch Otolaryngol 1981: 107: $1-11$

29. Grosheva M, Wittekindt C, Guntinas-Lichius O: Prognostic value of electroneurography and electromyography in facial palsy. Laryngoscope 2008: 118: 394-397
30. Ushio M, Kondo K, Takeuchi N, Tojima H, Yamaguchi T, Kaga K: Prediction of the prognosis of Bell's palsy using multivariate analyses. Otol Neurotol 2008: 29: 69-72

31. Lee HY, Byun JY, Park MS, Yeo SG: Effect of aging on the prognosis of Bell's palsy. Otol Neurotol 2013: 34: 766-770

32. Riga M, Kefalidis G, Danielides V: The role of diabetes mellitus in the clinical presentation and prognosis of Bell palsy. J Am Board Fam Med 2012: 25: 819-826

33. Kiziltan ME, Uluduz D, Yaman M, Uzun N: Electrophysiological findings of acute peripheral facial palsy in diabetic and non-diabetic patients. Neurosci Lett 2007: 418: 222-226

34. Savadi-Oskouei D, Abedi A, Sadeghi-Bazargani H: Independent role of hypertension in Bell's palsy: a case-control study. Eur Neurol 2008: 60: 253-257

35. Ilniczky S: Clinical analysis of patients with peripheral facial palsy. Ideggyogy Sz 2006: 59: 400-405 